\title{
Aerosol cyclosporin therapy in lung transplant recipients with bronchiolitis obliterans
}

\author{
A.T. Iacono*, T.E. Corcoran*, B.P. Griffith\#, W.F. Grgurich*, D.A. Smith*, A. Zeevi ${ }^{\ddagger}$, G.C. Smaldone ${ }^{\S}$, \\ K.R. McCurry ${ }^{+}$, B.A. Johnson*, J.H. Dauber*
}

Aerosol cyclosporin therapy in lung transplant recipients with bronchiolitis obliterans A.T. Iacono, T.E. Corcoran, B.P. Griffith, W.F. Grgurich, D.A. Smith, A. Zeevi, G.C. Smaldone, K.R. McCurry, B.A. Johnson, J.H. Dauber. (C)ERS Journals Ltd 2004.

ABSTRACT: The majority of patients who develop bronchiolitis obliterans, after lung transplantation, die within 2-3 yrs after onset since treatment with conventional immunosuppression is typically ineffective. A case/control study was conducted in lung transplant recipients with biopsy-documented bronchiolitis obliterans to determine whether aerosol cyclosporin use contributed to increased survival.

The cases comprised 39 transplant recipients who received open-label aerosol cyclosporin treatment in addition to conventional immunosuppression. The controls were transplant recipients treated with conventional immunosuppression alone. There were 51 controls from the University of Pittsburgh Medical Center and $\mathbf{1 0 0}$ from a large multicentric database (Novartis Lung Transplant Database).

Forced expiratory volume in one second expressed as a percentage of the predicted value was an independent predictor of survival in all patients with bronchiolitis obliterans. Cox proportional-hazards analysis revealed a survival advantage for aerosol cyclosporin cases compared to the Pittsburgh control group. A survival advantage was also seen when comparing study cases to multicentric controls.

Aerosol cyclosporin, given with conventional immunosuppression to lung transplant recipients with bronchiolitis obliterans, provides a survival advantage over conventional therapy alone.

Eur Respir J 2004; 23: 384-390.
Divisions of *Pulmonary, Allergy and Critical Care Medicine, ${ }^{+}$Cardiothoracic Surgery, and "Dept of Pathology, University of Pittsburgh, Pittsburgh, PA, \# Division of Cardiac Surgery, University of Maryland, Baltimore, MD, and ${ }^{\S}$ Division of Pulmonary and Critical Care Medicine, State University of New York at Stony Brook, Stony Brook, NY, USA.

Correspondence: A.T. Iacono, Division of Pulmonary, Allergy and Critical Care Medicine, University of Pittsburgh Medical Center, NW 628 Montefiore University Hospital, 3459 Fifth Ave., Pittsburgh, PA 15213, USA.

Fax: 14126477875

E-mail: iaconoat@msx.upmc.edu

Keywords: Aerosol cyclosporin, bronchiolitis obliterans, chronic rejection, lung transplantation, survival

Received: May 262003

Accepted after revision: October 82003

This study was supported, in part, by American Lung Association Grant No. CG-013-N.
The 3-yr survival after lung transplantation is 55\% [1]. More than half of all lung transplant recipients who survive $\geqslant 1 \mathrm{yr}$ develop chronic allograft rejection that is associated with bronchiolitis obliterans [2-5]. The development of bronchiolitis obliterans has a negative impact on long-term survival. No immunosuppressive regimen has been shown to prevent this complication or improve survival once it occurs [6-8].

Bronchiolitis obliterans is thought to be a consequence of immunological lung injury [9-11]. An inflammatory cascade directed against allograft bronchiolar epithelial and endothelial cells is initiated by T-lymphocytes, as demonstrated in animals [12-14] and human subjects [15, 16]. Alloreactive lymphocytes are found in bronchoalveolar lavage fluid, and selective T-cell clones are expanded during bronchiolitis obliterans [17]. Myriad cytokines and lymphocyte gene expression induce small airway inflammation, leading to myofibroblast-like cell proliferation and ingrowth of small airway granulation tissue, and resulting in occlusion of the airway lumen [18-21]. A cascade of injury and remodelling triggers a fibroproliferative process responsible for bronchiolar scarring and graft failure.

Cyclosporin is one of the mainstays of maintenance immunosuppression after transplantation; however, it has a narrow therapeutic index when given systemically [22]. It blocks lymphocyte activation by inhibiting transcription of cytokine genes in a dose-dependent manner [22, 23]. Cyclosporin also exerts an antifibrotic effect by inhibiting alveolar macrophage function and suppressing collagen deposition by lung fibroblasts [24, 25].

Previous investigations in animal lung transplant models demonstrated that aerosol cyclosporin produces higher concentrations of cyclosporin in lung tissue than does systemic administration and also decreases allograft inflammation associated with rejection [26-30]. The present authors have used aerosol cyclosporin to treat lung recipients with refractory rejection since 1991 [31]. Delivery of cyclosporin directly into the rejecting lung ameliorates small airway inflammation associated with bronchiolitis obliterans [32, 33]. In addition, pro-inflammatory cytokine gene expression in bronchoalveolar lavage cells decreases during treatment [34-36]. However, the therapeutic effect of aerosol cyclosporin is dependent on the dose deposited in the transplanted lung [36]. The present study demonstrates that aerosol cyclosporin also reduces the risk of death in patients with bronchiolitis obliterans.

\section{Materials and methods}

\section{Lung transplant recipients with bronchiolitis obliterans}

The present study was conducted at the University of Pittsburgh Medical Center, Pittsburgh, PA, USA. A total of 
538 lung transplant recipients from the Pittsburgh Lung Transplant Registry were screened and 129 were eligible for the study. The portion of this group that received open-label rescue treatment with aerosol cyclosporin constituted the study cases. The remainder, who did not meet entry criteria, were eligible to serve as controls (Pittsburgh control group) (fig. 1). A second control group was obtained from the Novartis Lung Transplant Database, Stanford, CA, USA $(\mathrm{n}=100)$ (fig. 2). This registry includes 826 lung transplant recipients from 12 major lung transplant centres throughout the world [37]. The study cases and both control groups underwent lung transplantation in the period January 1991March 2001 and were required to have biopsy-proven bronchiolitis obliterans. Identical criteria were used to select the Pittsburgh and multicentric control group patients, all of whom received conventional immunosuppression alone. Survival after bronchiolitis obliterans in the study cases was compared to the two distinct contemporaneous control groups.

\section{Variables affecting survival after bronchiolitis obliterans}

Variables potentially affecting survival after bronchiolitis obliterans were analysed in transplant recipients from the Pittsburgh Lung Transplant Registry $(n=129)$. Recipients were included if they met the following criteria: 1) receipt of a single lung, double lung or heart/lung transplant; 2) transplantation in the period January 1991-March 2001; 3) histological diagnosis of bronchiolitis obliterans; and 4) no retransplantation. The histological diagnosis of lung transplant rejection was made according to standard criteria [38]. A total

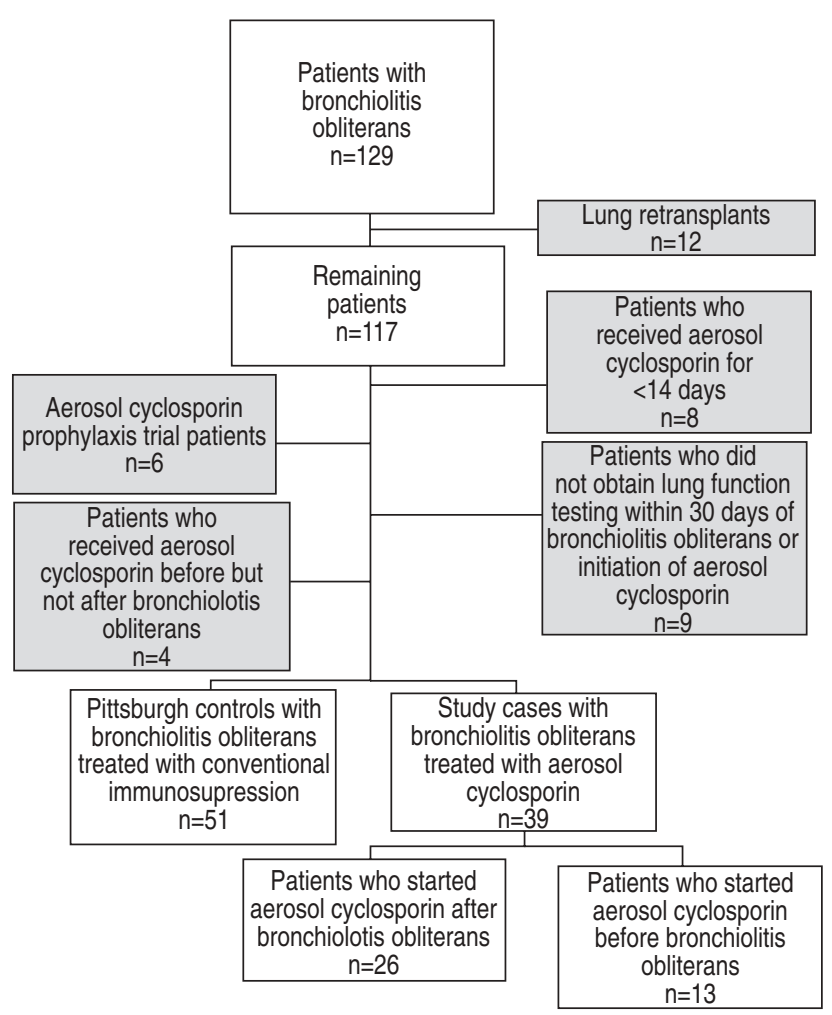

Fig. 1.-Selection criteria for lung transplant recipients from the Pittsburgh Lung Transplant Registry who underwent lung transplantation in the period January 1991-March 2001 and had biopsyproven bronchiolitis obliterans ( $\square$ : excluded patients). Cases who received aerosol cyclosporin were compared to Pittsburgh controls treated with conventional immunosuppression alone.

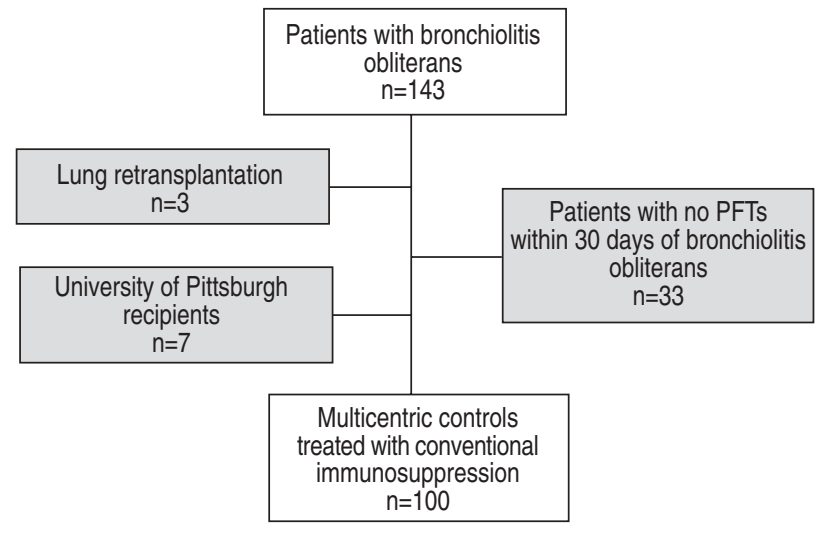

Fig. 2.-Selection criteria for lung transplant recipients from the Novartis Lung Transplant Database multicentric control group who underwent lung transplantation in the period January 1991-March 2001 and had biopsy-proven bronchiolitis obliterans ( $\square$ : excluded patients). PFT: pulmonary function test.

of 117 recipients met these criteria (fig. 1) (table 1). Ten variables were examined as possible predictors of survival (table 2). The determination of factors predictive of survival was performed using first univariate and then multivariate Cox proportional-hazards modelling.

\section{Aerosol cyclosporin patient selection criteria}

The Institutional Review Board of the University of Pittsburgh approved aerosol cyclosporin as open-label rescue treatment for refractory allograft rejection. In order to be eligible to receive aerosol cyclosporin, patients were required to experience refractory rejection. Refractory rejection was

Table 1.-Baseline characteristics of lung transplant recipients with bronchiolitis obliterans (BO) from the Pittsburgh Lung Transplant Registry used to analyse possible predictors of survival

Females/males $n$

$69 / 48$

Indication for transplantation

Emphysema

Cystic fibrosis

$44(38)$

Fibrotic lung disease

Primary pulmonary hypertension

$20(17)$

$17(15)$

Other

$10(8)$

Type of transplant

Single lung

$26(22)$

Double lung

$60(51)$

Heart/lung

$47(40)$

Bronchiolitis obliterans

Age at diagnosis yrs

Time after transplant of

$44.4 \pm 13.2$

diagnosis days

FEV ${ }^{\#} \%$ pred

Acute rejection ${ }^{\top}$ events before $\mathrm{BO}$

$727 \pm 639 ; 524(318-936)$

$53 \pm 23$

$3.9 \pm 2.5 ; 4(2-5)$

Data are presented as $\mathrm{n}(\%)$, mean $\pm \mathrm{SD}$ or median (interquartile range). FEV1: forced expiratory volume in one second; $\%$ pred: per cent predicted. "\#: measured at initiation of aerosol cyclosporin (AC) therapy (cases who received AC only after histological confirmation of BO) or at time of histological diagnosis of $\mathrm{BO}$ (controls and all other cases); $\tau_{\text {: }}$ at least grade 2 acute cellular rejection, i.e. mild rejection typically treated with pulsed methylprednisolone or antithymocyte globulin. 
Table 2. - Univariate and multivariate analysis of factors affecting survival after bronchiolitis obliterans (BO)

\begin{tabular}{|c|c|c|c|c|}
\hline & \multicolumn{2}{|c|}{ Univariate analysis } & \multicolumn{2}{|c|}{ Multivariate analysis } \\
\hline & $\operatorname{HR}(95 \% \mathrm{CI})$ & p-value & HR $(95 \% \mathrm{CI})$ & p-value \\
\hline $\mathrm{FEV}_{1} \# \%$ pred & $0.98(0.96-0.99)$ & $<0.001$ & $0.97(0.96-0.99)$ & $<0.001$ \\
\hline \multicolumn{5}{|l|}{ Lung transplantation date } \\
\hline 1991-1993 versus $1994-1996$ & $1.12(0.62-2.03)$ & 0.70 & $1.08(0.58-2.03)$ & 0.81 \\
\hline 1991-1993 versus 1997-2001 & $1.21(0.46-3.14)$ & 0.70 & $1.10(0.38-3.18)$ & 0.86 \\
\hline Time after transplant of $\mathrm{BO}$ diagnosis days & $1.00(1.00-1.00)$ & 0.54 & $1.00(0.99-1.00)$ & 0.63 \\
\hline \multicolumn{5}{|l|}{ Transplant type } \\
\hline Double versus single & $1.31(0.80-2.16)$ & 0.29 & $1.62(0.95-2.77)$ & 0.08 \\
\hline Heart/lung versus single & $1.67(0.73-3.81)$ & 0.22 & $2.40(1.04-5.56)$ & 0.04 \\
\hline Blood creatinine level at $\mathrm{BO}$ diagnosis & $1.03(0.81-1.33)$ & 0.77 & $1.05(0.81-1.36)$ & 0.72 \\
\hline Female sex & $0.77(0.48-1.24)$ & 0.29 & $0.85(0.51-1.41)$ & 0.53 \\
\hline Age at $\mathrm{BO}$ diagnosis yrs & $1.00(0.98-1.02)$ & 0.90 & $1.00(0.98-1.02)$ & 0.81 \\
\hline Acute rejection events before $\mathrm{BO} \mathrm{n}$ & $0.98(0.89-1.08)$ & 0.76 & $0.96(0.87-1.05)$ & 0.36 \\
\hline Acute rejection ${ }^{\top}$ events-pre-BO biopsy ${ }^{-1+}$ & $0.72(0.23-2.21)$ & 0.57 & $0.71(0.22-2.30)$ & 0.57 \\
\hline Acute rejection events $\cdot$ pre-BO $\mathrm{yr}^{-1}$ & $1.01(0.95-1.07)$ & 0.67 & $1.00(0.93-1.06)$ & 0.91 \\
\hline
\end{tabular}

HR: hazard ratio; CI: confidence interval; FEV1: forced expiratory volume in one second; \% pred: per cent predicted. ${ }^{\#}$ : measured at initiation of aerosol cyclosporin (AC) therapy (cases who received AC only after histological confirmation of $\mathrm{BO}$ ) or at time of histological diagnosis of $\mathrm{BO}$ (controls and all other cases); ": at least grade 2 acute cellular rejection, i.e. mild rejection typically treated with pulsed methylprednisolone or antithymocyte globulin; ${ }^{+}$: ratio of acute rejection events to routine surveillance biopsy procedures before BO diagnosis, a measure of high-grade acute rejection frequency.

defined according to the following three criteria: 1) two or more consecutive histological rejection events (active bronchiolitis obliterans, at least grade 2 acute rejection and/or lymphocytic bronchitis/bronchiolitis); 2) $\geqslant 10 \%$ decline in forced expiratory volume in one second (FEV1) expressed as a percentage of the predicted value from the best baseline value; and 3) failure to improve histologically following conventional immunosupressive therapy. Of the 129 recipients with bronchiolitis obliterans from the Pittsburgh Lung Transplant Registry, those who received aerosol cyclosporin were the study cases $(n=39)$ (fig. 1). Study cases were included if they met the following criteria: 1) receipt of aerosol cyclosporin for $\geqslant 14$ days; 2) receipt of aerosol cyclosporin after histological confirmation of bronchiolitis obliterans if treatment commenced prior to this diagnosis; 3) pulmonary function tests carried out within 30 days of either the diagnosis of bronchiolitis obliterans or initiation of aerosol cyclosporin; and 4) nonparticipation in other aerosol cyclosporin protocols. Of the 39 study cases, 26 received aerosolised cyclosporin only after histological confirmation of bronchiolitis obliterans and 13 prior to confirmation of bronchiolitis obliterans. Only four subjects who began treatments with aerosol cyclosporin were unable to continue with treatment for $\geqslant 2$ weeks due to cough, dyspnoea and other symptoms of upper airway irritation.

\section{Administration of aerosol cyclosporin}

Aerosol cyclosporin was delivered from a jet nebuliser (AeroTech II; Cis-Us, Bedford, MA, USA) containing $300 \mathrm{mg}$ drug daily for 10 days followed by $300 \mathrm{mg}$ three times per week, on Mondays, Wednesdays and Fridays [8]. Cyclosporin powder (Novartis Pharmaceuticals, East Hanover, NJ, USA) was dissolved in propylene glycol at a concentration of $62.5 \mathrm{mg} \cdot \mathrm{mL}^{-1}$.

\section{Immunosuppressive regimens}

Maintenance immunosuppression consisted of oral cyclosporin or tacrolimus, azathioprine or mycophenolate mofetil, and prednisone. Enhanced immune suppression for treatment of acute rejection (at least grade 2) and/or active bronchiolitis obliterans consisted of pulse corticosteroids (intravenous methylprednisolone, $1 \mathrm{~g} \cdot \mathrm{day}^{-1}$ for 3 days, or oral prednisone, $100 \mathrm{mg}$ tapered to $10 \mathrm{mg}$ over 14 days), equine antilymphocyte globulin (Atgam; Pharmacia, Kalamazoo, MI, USA; $15 \mathrm{mg} \cdot \mathrm{kg}$ body weight ${ }^{-1} \cdot \mathrm{day}^{-1}$ for 7 days) or rabbit antithymocyte globulin (Thymoglobulin; Sangstat, Fremont, CA, USA; $1.5 \mathrm{mg} \cdot \mathrm{kg}$ body weight ${ }^{-1} \cdot \mathrm{day}^{-1}$ for $5-7$ days).

\section{Statistical considerations in determining the effect of aerosol cyclosporin on survival}

The primary goal was to determine whether or not aerosol cyclosporin improved survival after diagnosis of bronchiolitis obliterans. Overall survival time was determined from the initiation of aerosol cyclosporin in the 26 patients with confirmed bronchiolitis obliterans prior to receiving aerosol cyclosporin, and on the day of histological confirmation of bronchiolitis obliterans in the 13 patients who received aerosol cyclosporin prior to diagnosis of bronchiolitis obliterans. In both control groups, survival time was determined from the date bronchiolitis obliterans was confirmed. Baseline FEV1 (as a percentage of the predicted value) and bronchiolitis obliterans syndrome grades for each subject were similarly determined on the date of either aerosol cyclosporin initiation or confirmation of bronchiolitis obliterans, using the criteria described above. Overall survival was assessed in the 39 aerosol cyclosporin cases and the 51 Pittsburgh and 100 multicentric control patients using the Kaplan-Meier method, and comparisons were made using the log-rank test [39].

Cox proportional-hazards modelling was then used to account for potential confounders in the analysis, and to generate a final assessment of the effect of aerosol cyclosporin on survival. Factors determined to be significant predictors of survival in the Pittsburgh Lung Transplant Registry group were included in the model, as was a variable intended to gauge the extent of refractory rejection, the condition that originally resulted in the cases receiving aerosol cyclosporin. It was decided a priori that the number of at least grade 2 
rejection events per year prior to diagnosis of bronchiolitis obliterans would best serve this function. Analyses were performed in all 39 aerosol cyclosporin study cases and in the subgroup of 26 cases who received aerosol cyclosporin after histological confirmation of bronchiolitis obliterans. (These study cases were compared independently to both the Pittsburgh and multicentric control groups.) Estimates of the hazard ratio with $95 \%$ confidence intervals were calculated [40].

\section{Results}

\section{Characteristics of the patients}

The study population comprised 39 cases and 151 controls (table 3). Aerosol cyclosporin was administered for a mean duration of $69.9 \pm 66.3$ weeks. Twenty-five $(64.1 \%)$ cases demonstrated a reduction in their grade of rejection by transbronchial biopsy within 90 days after initiation of aerosol cyclosporin treatment. The baseline FEV1 was lower in the aerosol cyclosporin cases than in the Pittsburgh and multicentric controls ( $45 \pm 16$ versus $56 \pm 26$ and $53 \pm 21 \%$ pred $(\mathrm{p}=0.03$ and $\mathrm{p}=0.04)$, respectively). Acute rejection was more common prior to the onset of bronchiolitis obliterans in study cases compared to Pittsburgh and multicentric controls (4.8 versus 3.2 and 1.4 at least grade 2 rejection events, respectively). Bronchiolitis obliterans syndrome, at baseline, was more prevalent in the aerosol cyclosporin group than in the Pittsburgh controls ( 79 versus $55 \%, \mathrm{p}=0.02$ by Chi-squared test), and similar in proportion to that in the multicentric controls $(70 \%, \mathrm{p}=0.26)$. The number of cytomegalovirus mismatches (donor negative/recipient positive) was similar in cases versus Pittsburgh controls ( 9 versus $12, \mathrm{p}=0.15$ ). There was no difference in cytomegalovirus disease after bronchiolitis
Table 4.-Comparison of baseline immunosuppression and antiviral prophylaxis between aerosol cyclosporin cases and Pittsburgh controls

\begin{tabular}{|c|c|}
\hline Aerosol cyclosporin cases versus Pit & p-value ${ }^{\#}$ \\
\hline \multicolumn{2}{|l|}{ Medication use } \\
\hline Tacrolimus and oral cyclosporin & 0.11 \\
\hline Azathioprine & 0.48 \\
\hline Mycophenolate mofetil & 0.25 \\
\hline Aciclovir & 0.37 \\
\hline Ganciclovir & 0.15 \\
\hline Valganciclovir & 0.44 \\
\hline \multicolumn{2}{|l|}{ Dose } \\
\hline Tacrolimus & 0.93 \\
\hline Oral cyclosporin & 0.59 \\
\hline Oral prednisone & 0.65 \\
\hline Azathioprine & 0.27 \\
\hline \multicolumn{2}{|c|}{$\begin{array}{l}\text { \#: Chi-squared test for proportion of subjects using medications and } \\
\text { unpaired t-test for dose on day of bronchiolitis obliterans diagnosis. }\end{array}$} \\
\hline \multicolumn{2}{|c|}{ obliterans or aerosol cyclosporin, based on bronchoalveolar } \\
\hline \multirow{3}{*}{\multicolumn{2}{|c|}{$\begin{array}{l}\text { lavage culture or histology in cases and Pittsburgh controls } \\
\text { (four cases identified histologically in both groups). Bronch- } \\
\text { iolitis obliterans was detected earlier after transplantation in } \\
\text { aerosol cyclosporin cases compared to the Pittsburgh controls. }\end{array}$}} \\
\hline & \\
\hline & \\
\hline \multicolumn{2}{|c|}{ However, this difference was nonsignificant $(688 \pm 524$ versus } \\
\hline \multicolumn{2}{|c|}{$\begin{array}{l}844 \pm 686 \text { days after transplant, } \mathrm{p}=0.28 \text { ). Baseline immuno- } \\
\text { suppression and antiviral prophylaxis were similar in the }\end{array}$} \\
\hline \multicolumn{2}{|c|}{$\begin{array}{l}\text { study and control cases in terms of their use of the basic } \\
\text { medications and their dosing, and mean tacrolimus and }\end{array}$} \\
\hline \multicolumn{2}{|c|}{$\begin{array}{l}\text { cyclosporin levels after bronchiolitis obliterans diagnosis were } \\
\text { similar in cases and Pittsburgh controls (14.1 } \pm 3.5 \text { versus }\end{array}$} \\
\hline & \\
\hline
\end{tabular}

Table 3. - Baseline characteristics of aerosol cyclosporin (AC) cases and Pittsburgh and multicentric control groups

\begin{tabular}{|c|c|c|c|c|}
\hline & \multicolumn{2}{|c|}{ Cases } & \multicolumn{2}{|c|}{ Controls } \\
\hline & Total & $\mathrm{AC}$ after $\mathrm{BO}^{\#}$ & Pittsburgh & Multicentric \\
\hline Females/males $\mathrm{n}$ & $24 / 15$ & $18 / 8$ & $31 / 20$ & $46 / 54$ \\
\hline \multicolumn{5}{|l|}{ Indication for transplantation } \\
\hline Emphysema & $9(23)$ & $4(15)$ & $22(43)$ & $36(36)$ \\
\hline Cystic fibrosis & $10(26)$ & $8(31)$ & $6(11)$ & $20(20)$ \\
\hline Fibrotic lung disease & $11(28)$ & $7(27)$ & $5(10)$ & $13(13)$ \\
\hline Primary pulmonary hypertension & $2(5)$ & $1(4)$ & $8(16)$ & $14(14)$ \\
\hline Other & 7 (18) & $6(23)$ & $10(20)$ & $17(17)$ \\
\hline \multicolumn{5}{|l|}{ Type of transplant } \\
\hline Single lung & $19(49)$ & $12(46)$ & $30(59)$ & $50(50)$ \\
\hline Double lung & $18(46)$ & $13(50)$ & $14(27)$ & $25(25)$ \\
\hline Heart/lung & $2(5)$ & $1(4)$ & $7(14)$ & $25(25)$ \\
\hline \multicolumn{5}{|l|}{ Bronchiolitis obliterans } \\
\hline Age at diagnosis yrs & $40.6 \pm 13.3$ & $38.8 \pm 13.1$ & $45.1 \pm 13.1$ & $43.3 \pm 13.2$ \\
\hline Time after transplant of diagnosis days & $\begin{array}{c}688 \pm 524 ; \\
557(321-820)\end{array}$ & $\begin{array}{c}519 \pm 388 ; \\
460(260-646)\end{array}$ & $\begin{array}{c}844 \pm 686 \\
585(348-1106)\end{array}$ & $\begin{array}{c}616 \pm 379 \\
544(315-901)\end{array}$ \\
\hline $\mathrm{FEV}_{1}^{+} \%$ pred & $45 \pm 16$ & $47 \pm 16$ & $56 \pm 26$ & $53 \pm 21$ \\
\hline Acute rejection events before $\mathrm{BO}$ & $\begin{array}{c}4.8 \pm 3.0 \\
4(4-7)\end{array}$ & $\begin{array}{l}3.8 \pm 2.2 \\
3(2-6)\end{array}$ & $\begin{array}{l}3.2 \pm 1.9 \\
3(2-4)\end{array}$ & $\begin{array}{l}1.4 \pm 1.5 \\
1(0-2)\end{array}$ \\
\hline Grade $3 \mathrm{BOS}^{+}$ & $8(21)$ & $4(15)$ & $8(15)$ & $21(21)$ \\
\hline Grade $2 \mathrm{BOS}^{+}$ & $8(21)$ & $6(23)$ & $10(20)$ & $18(18)$ \\
\hline Grade $1 \mathrm{BOS}^{+}$ & $15(37)$ & $10(39)$ & $10(20)$ & $31(31)$ \\
\hline $\mathrm{No} \mathrm{BOS}^{+}$ & $8(21)$ & $6(23)$ & $23(45)$ & $30(30)$ \\
\hline AC therapy duration weeks & $69.9 \pm 66.3$ & $71.5 \pm 0.7$ & NA & NA \\
\hline Time between diagnosis and AC therapy weeks & NA & $36.4 \pm 36.1$ & NA & NA \\
\hline
\end{tabular}

Data are presented as $\mathrm{n}(\%)$, mean $\pm \mathrm{SD}$ or median (interquartile range). BO: bronchiolitis obliterans; FEV1: forced expiratory volume in one second; BOS: bronchiolitis obliterans syndrome [41]; \% pred: per cent predicted; NA: not applicable. ${ }^{\#}$ : AC received only after histological confirmation of BO; ${ }^{\top}$ : at least grade 2 acute cellular rejection, i.e. mild rejection typically treated with pulsed methylprednisolone or antithymocyte globulin; ${ }^{+}$: measured at initiation of AC therapy (cases who received AC only after histological confirmation of BO) or at time of histological diagnosis of BO (controls and all other cases). 


\section{Kaplan-Meier survival analysis}

Kaplan-Meier estimates of survival are shown in figure 3. Median survival was $4.5 \mathrm{yrs}$ in aerosol cyclosporin cases $(n=39), 2.4$ yrs in Pittsburgh controls and 2.3 yrs in multicentric controls. Median survival in the 26 cases who started aerosol cyclosporin therapy after bronchiolitis obliterans diagnosis was $4.5 \mathrm{yrs}$.

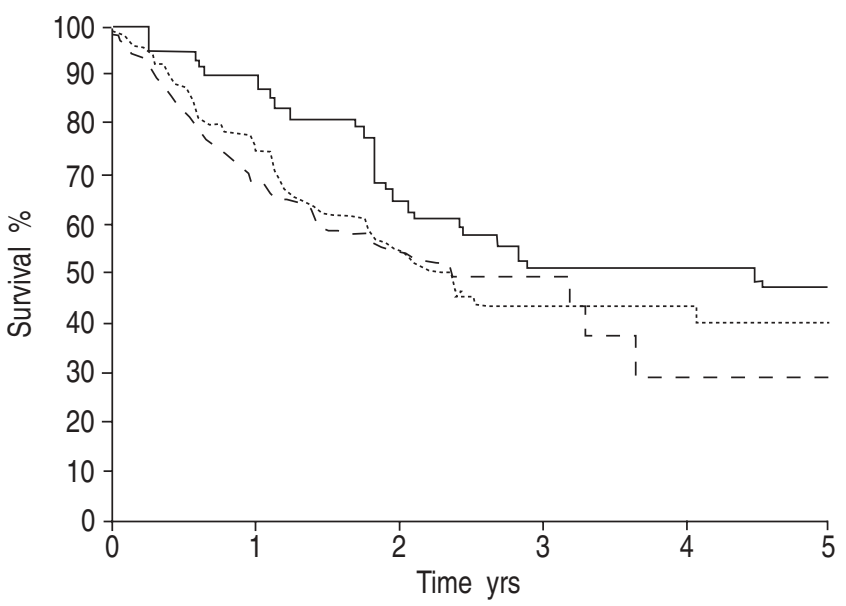

Fig. 3. - Kaplan-Meier survival estimates for aerosol cyclosporin (AC) cases $(-; \mathrm{n}=39)$ and the Pittsburgh $(\cdots \ldots \ldots \ldots ; n=51)$ and multicentric (- - - ; $n=100)$ control groups. Survival was estimated from the initiation of $\mathrm{AC}$ therapy (cases who received $\mathrm{AC}$ only after histological confirmation of bronchiolitis obliterans (BO)) or time of histological diagnosis of $\mathrm{BO}$ (controls and all other cases). The p-values obtained at $1,2,3,4$ and 5 yrs were $0.11,0.21,0.23,0.23$ and 0.26 for the Pittsburgh controls and $0.02,0.12,0.22,0.08$ and 0.09 for the muticentric controls, respectively (log-rank test).

\section{Proportional-hazards modelling of prognostic factors}

Factors potentially predictive of survival after bronchiolitis obliterans diagnosis were analysed in all 117 patients from the Pittsburgh Lung Transplant Registry (table 2). Preservation of FEV1 (as a percentage of the predicted value) was associated with a reduced risk of death (hazard ratio 0.98, $\mathrm{p}<0.001)$. When FEV1 was included in a multivariate model, a trend towards better survival was noted in single lung versus heart/lung (hazard ratio 2.40, $\mathrm{p}=0.04$ ) and double lung (hazard ratio $1.62, \mathrm{p}=0.08$ ) recipients. Importantly, no significant differences in survival risk were noted between date of transplantation intervals (1991-1993, 1994-1996 and 1997-2001) or the time after transplant (in days) of bronchiolitis obliterans diagnosis (table 2).

\section{Multivariate survival analysis}

Table 5 shows the results of the Cox proportional-hazards model of the effect of aerosol cyclosporin on survival after a histological diagnosis of bronchiolitis obliterans. Aerosol cyclosporin was associated with improved survival compared to the Pittsburgh controls (hazard ratio 0.48, $\mathrm{p}=0.03$ ). A similar survival advantage, approaching significance, was evident in the subgroup of 26 cases who received aerosol cyclosporin only after diagnosis of bronchiolitis obliterans (hazard ratio $0.49, \mathrm{p}=0.06$ ). Survival benefit was also demonstrated for the entire study group and the subgroup compared to multicentric controls (hazard ratio $0.40(\mathrm{p}=0.01)$ and 0.41 ( $\mathrm{p}=0.03)$, respectively). The cyclosporin cases demonstrated a similar advantage when compared to the combined control group (hazard ratio $0.46, \mathrm{p}=0.01$ ).

Table 5. - Results of Cox proportional-hazards model considering survival after a histological diagnosis of bronchiolitis obliterans (BO) in both aerosol cyclosporin (AC) cases and controls

\begin{tabular}{|c|c|c|c|c|}
\hline Cases & Controls & & Hazard ratio $(95 \% \mathrm{CI})$ & $\mathrm{p}$-value \\
\hline \multirow[t]{12}{*}{$\mathrm{AC}$ after $\mathrm{BO}^{\#}$} & Pittsburgh & Aerosol cyclosporin & $0.49(0.23-1.03)$ & 0.06 \\
\hline & & $\mathrm{FEV}^{+} \%$ pred & $0.97(0.96-0.99)$ & 0.001 \\
\hline & & Acute rejection ${ }^{\curvearrowleft}$ events $\cdot \mathrm{yr}^{-1}$ & $0.95(0.85-1.05)$ & 0.31 \\
\hline & & Transplant type & & \\
\hline & & Double versus single & $2.01(0.99-4.09)$ & 0.05 \\
\hline & & Heart/lung versus single & $2.28(0.84-6.17)$ & 0.10 \\
\hline & Multicentric & Aerosol cyclosporin & $0.41(0.19-0.89)$ & 0.03 \\
\hline & & $\mathrm{FEV}^{+} \%$ pred & $0.96(0.94-0.98)$ & $<0.001$ \\
\hline & & Acute rejection ${ }^{\top}$ events $\cdot \mathrm{yr}^{-1}$ & $0.98(0.90-1.08)$ & 0.75 \\
\hline & & Transplant type & & \\
\hline & & Double versus single & $1.24(0.69-2.23)$ & 0.48 \\
\hline & & Heart/lung versus single & $1.11(0.51-2.45)$ & 0.79 \\
\hline \multirow[t]{12}{*}{ Total } & Pittsburgh & Aerosol cyclosporin & $0.48(0.25-0.93)$ & 0.03 \\
\hline & & $\mathrm{FEV}^{+} \%$ pred & $0.97(0.96-0.99)$ & $<0.001$ \\
\hline & & Acute rejection ${ }^{\top}$ events $\cdot \mathrm{yr}^{-1}$ & $0.96(0.87-1.06)$ & 0.40 \\
\hline & & Transplant type & & \\
\hline & & Double versus single & $1.85(0.96-3.57)$ & 0.07 \\
\hline & & Heart/lung versus single & $1.54(0.81-5.82)$ & 0.12 \\
\hline & Multicentric & Aerosol cyclosporin & $0.40(0.20-0.77)$ & 0.01 \\
\hline & & $\mathrm{FEV}^{+} \%$ pred & $0.96(0.94-0.98)$ & $<0.001$ \\
\hline & & Acute rejection ${ }^{\top}$ events $\cdot \mathrm{yr}^{-1}$ & $0.99(0.91-1.08)$ & 0.88 \\
\hline & & Transplant type & & \\
\hline & & Double versus single & $1.19(0.86-2.09)$ & 0.54 \\
\hline & & Heart/lung versus single & $1.12(0.51-2.44)$ & 0.78 \\
\hline
\end{tabular}

FEV1: forced expiratory volume in one second; pred: per cent predicted. ${ }^{\#}$ : AC received only after histological confirmation of BO; ${ }^{\top}$ : at least grade 2 acute cellular rejection, i.e. mild rejection typically treated with pulsed methylprednisolone or antithymocyte globulin; ${ }^{+}$: measured at initiation of AC therapy (cases who received AC only after histological confirmation of BO) or at time of histological diagnosis of $\mathrm{BO}$ (controls and all other cases). 


\section{Discussion}

The present results indicate that aerosol cyclosporin improves survival among lung transplant recipients with bronchiolitis obliterans. Only patients with biopsy-proven bronchiolitis obliterans were included since a precise assessment of survival time was dependent on the specificity of this diagnosis. Median survival was $\sim 2$ yrs longer in recipients who received aerosol cyclosporin than in the Pittsburgh and multicentric controls, and a trend approaching significance was demonstrated using the log-rank test (4.5 versus 2.4 and 2.3 yrs ( $\mathrm{p}=0.21$ and $\mathrm{p}=0.09)$, respectively). In support of the reliability of these data, the median survival in both control populations was very similar, and almost identical to the published median survival of lung transplant recipients with bronchiolitis obliterans syndrome from the Barnes-Jewish Hospital in St Louis (MO, USA) [9], a centre with one of the largest experiences in lung transplantation in the USA.

Covariates that might influence survival after bronchiolitis obliterans were analysed in 117 patients with biopsy-proven bronchiolitis obliterans chosen from the Pittsburgh Lung Transplant Registry. The degree of lung function impairment was a significant predictor of mortality. Heart/lung and double lung transplant recipients were at increased risk of death after the onset of bronchiolitis obliterans compared to single lung transplant recipients. A multivariate model was utilised in order to determine the effect of aerosol cyclosporin on survival. Variables shown to predict survival after a diagnosis of bronchiolitis obliterans were included as potential confounders, as was a variable gauging the extent of refractory rejection, the primary enrolment condition for the original open-label study of aerosol cyclosporin (though not an independent predictor of survival after bronchiolitis obliterans based on the current model). The model indicates that the risk of death among all cases who received aerosol cyclosporin was reduced by $\sim 50 \%$ compared to the Pittsburgh controls. A similar reduction in fatal outcomes was observed in the subgroup of 26 patients who received aerosol cyclosporin only after confirmation of bronchiolitis obliterans. Furthermore, a comparable reduction in the risk of death was evident when the control group was derived exclusively from the Novartis Lung Transplant Database.

Survival after bronchiolitis obliterans correlates with the extent of functional deterioration of the lung allograft. FEV1, expressed as a percentage of the predicted value, appears to represent a reliable physiological marker of the morphological extent of small airway pathology, with successful management being dependent on the degree of reversible active airway inflammation as opposed to bronchiolar fibrosis. In addition, single lung recipients demonstrated a survival benefit compared to heart/lung and double lung transplant recipients. The native lung, under the circumstances of bronchiolitis obliterans, could offer a protective effect since functional deterioration in the native lung is slow compared to the relatively rapid deterioration of the allograft associated with bronchiolitis obliterans. The native lung may also benefit from the systemic immunosuppressive effects of systemic cyclosporin or tacrolimus in patients transplanted for immunologically mediated lung disease [42].

The present study assessed the association between the clinical use of aerosol cyclosporin and survival using a prospectively defined hypothesis and methods of data collection. Conducting such a trial at a single transplant centre was necessary since a multicentric trial was not logistically feasible, lung transplant programmes typically do not have experience in aerosol drug development and the dry-powder cyclosporin necessary to constitute aerosol cyclosporin was available in limited supply. The duration of the trial and follow-up were consequently very long (10 yrs). As it is recognised that refractory lung transplant rejection is associated with very poor outcomes, patient selection was not randomised and open-label therapy was given. Given the inherent imperfections of such a study design, substantial effort was made to ensure a proper comparison between cases and controls. This included the use of multivariate models along with the careful inclusion of matching factors, as previously described, and the use of two contemporary and independent control groups.

In summary, the present results support the administration of aerosol cyclosporin to lung transplant patients with bronchiolitis obliterans. Owing to the recognised limitations of a case/control study, future randomised studies should be performed using aerosol cyclosporin for bronchiolitis obliterans, and incorporating incremental drug dosing and measurement of allograft drug deposition to formalise a dose/response relationship and optimise patient benefit [36, $43,44]$.

\footnotetext{
Acknowledgements. The authors are indebted to R.R.E. Morris and T.T.R. Brazelton of Stanford University (Stanford, CA, USA) for access to the Novartis Lung Transplant Database, Novartis Pharmaceuticals (East Hanover, NJ, USA) for kindly supplying cyclosporin powder to conduct this study, and M.P. Donahoe of the University of Pittsburgh (Pittsburgh, PA, USA) and K.E.A. Burns of the London Health Sciences Centre (London, Canada) for their thoughtful review of this manuscript.
}

\section{References}

1. Lin HM, Kauffman HM, McBride MA, et al. Center-specific graft and patient survival rates: 1997 United Network for Organ Sharing (UNOS) report. JAMA 1998; 280: 11531160.

2. Bando K, Paradis IL, Similo S, et al. Obliterative bronchiolitis after lung and heart-lung transplantation. An analysis of risk factors and management. $J$ Thorac Cardiovasc Surg 1995; 110: 4-13 (discussion 13-14).

3. Sharples LD, Tamm M, McNeil K, Higenbottam TW, Stewart S, Wallwork J. Development of obliterative bronchiolitis syndrome in recipients of heart-lung transplantation early risk factors. Transplantation 1996; 61: 560-566.

4. Hosenpud JD, Bennett LE, Keck BM, Fiol B, Boucek MM, Novick RJ. The Registry of the International Society for Heart and Lung Transplantation: fifteenth official report 1998. J Heart Lung Transplant 1998; 17: 656-668.

5. Trulock EP. Management of lung transplant rejection. Chest 1993; 103: 1566-1576.

6. Kesten S, Maidenberg A, Winton T, Maurer J. Treatment of presumed and proven acute rejection following six months of lung transplant survival. Am J Respir Crit Care Med 1995; 152: 1321-1324.

7. Trulock EP. Lung transplantation. Am J Respir Crit Care Med 1997; 155: 789-818.

8. Paradis I, Yousem S, Griffith B. Airway obstruction and bronchiolitis obliterans after lung transplantation. Clin Chest Med 1993; 14: 751-763.

9. Date H, Lynch JP, Sundaresan S, Patterson GA, Trulock EP. The impact of cytolytic therapy on bronchiolitis obliterans syndrome. J Heart Lung Transplant 1998; 17: 869-875.

10. Valentine CV, Robbins RC, Berry GJ, et al. Actuarial survival of heart-lung and bilateral sequential lung transplant recipients with obliterative bronchiolitis. J Heart Lung Transplant 1996; 15: 371-383.

11. Sharples LD, McNeil K, Stewart S, Wallwork J. Risk factors 
for bronchiolitis obliterans: a systematic review of recent publications. J Heart Lung Transplant 2002; 21: 271-281.

12. Neuringer IP, Walsh SP, Mannon RB, Gabriel S, Aris RM. Enhanced $\mathrm{T}$ cell cytokine gene expression in mouse airway obliterative bronchiolitis. Transplantation 2000; 69: 399-405.

13. Hirt SW, You XM, Moller F, et al. Development of obliterative bronchiolitis after allogenic rat lung transplantation: implication of acute rejection and the time point of treatment. J Heart Lung Transplant 1999; 18: 542-548.

14. Tikkanen JM, Lemstrom KB, Koskinen PK. Blockade of CD28/B7-2 costimulation inhibits experimental obliterative bronchiolitis in rat tracheal allografts: suppression of helper T cell type1-dominated immune response. Am J Respir Crit Care Med 2002; 165: 724-729.

15. Duncan SR, Leonard C, Theodore J, et al. Oligoclonal CD4(+) T cell expansions in lung transplant recipients with obliterative bronchiolitis. Am J Respir Crit Care Med 2002; 165: 1439-1444.

16. Duncan SR, Valentine V, Roglic $\mathrm{M}$, et al. $\mathrm{T}$ cell receptor biases and clonal proliferations among lung transplant recipients with obliterative bronchiolitis. J Clin Invest 1996; 97: 2642-2650.

17. Rabinowich H, Zeevi A, Paradis IL, et al. Proliferative responses of bronchoalveolar lavage lymphocytes from heart-lung transplant patients. Transplantation 1990; 49: $115-121$.

18. El-Gamel A, Sim E, Hasleton P, et al. Transforming growth factor beta (TGF- $\beta$ ) and obliterative bronchiolitis following pulmonary transplantation. J Heart Lung Transplant 1999; 18: 828-837.

19. Sundaresan S, Alevy YG, Steward N, et al. Cytokine gene transcripts for tumor necrosis factor alpha, interleukin-2, and interferon-gamma in human pulmonary allografts. J Heart Lung Transplant 1995; 14: 512-518.

20. Whitehead BF, Stoehr C, Wu CJ, et al. Cytokine gene expression in human lung transplant recipients. Transplantation 1993; 56: 956-961.

21. Clement MV, Legros-Maida $\mathrm{S}$, Israel-Biet $\mathrm{D}$, et al. Perforin and granzyme $\mathrm{B}$ expression is associated with severe acute rejection. Evidence for in situ localization in alveolar lymphocytes of lung-transplanted patients. Transplantation 1994; 57: 322-326.

22. DiPadova FE. Pharmacology of cyclosporine (Sandimmune). V. Pharmacological effects on immune function: in vitro studies. Pharmacol Rev 1989; 41: 373-405.

23. Garcia JEL, Rodriguez FM, Lopez AJ, et al. Effect of cyclosporin A on inflammatory cytokine production by human alveolar macrophages. Respir Med 1998; 92: 722-728.

24. Kovacs EJ, Kelley J. Lymphokine regulation of macrophage-derived growth factor secretion following pulmonary injury. Am J Pathol 1985; 121: 261-268.

25. Eickelberg O, Pansky A, Koehler E, et al. Molecular mechanisms of TGF- $\beta$ antagonism by interferon and cyclosporine A in lung fibroblasts. FASEB $J$ 2001; 15: 797-806.

26. Mitruka SN, Won A, McCurry KR, et al. In the lung aerosol cyclosporine provides a regional concentration advantage over intramuscular cyclosporine. J Heart Lung Transplant 2000; 19: 969-975.

27. Muggenberg BA, Hoover MD, Griffith BP. Administration of cyclosporine by inhalation: a feasibility study in beagle dogs. J Aerosol Med 1990; 3: 1-6.
28. Dowling R D, Zenati M, Burckart GJ, et al. Aerosolized cyclosporine as single-agent immunotherapy in canine lung allografts. Surgery 1990; 108: 198-204 (discussion 204-205).

29. Keenan RJ, Duncan AJ, Yousem SA, et al. Improved immunosuppression with aerosolized cyclosporine in experimental pulmonary transplantation. Transplantation 1992; 53: $20-25$.

30. O'Riordan TG, Duncan SR, Burckart GJ, Griffith, Smaldone GC. Production of an aerosol of cyclosporine: a prelude to clinical studies. J Aerosol Med 1992; 5: 171177.

31. Iacono AT, Keenan RJ, Duncan SR, et al. Aerosolized cyclosporine in lung recipients with refractory chronic rejection. Am J Respir Crit Care Med 1996; 153: 1451-1455.

32. O'Riordan TG, Iacono A, Keenan RJ, et al. Delivery and distribution of aerosolized cyclosporine in lung allograft recipients. Am J Respir Crit Care Med 1995; 151: 516-521.

33. Keenan RJ, Zeevi A, Iacono AT, et al. Efficacy of inhaled cyclosporine in lung transplant recipients with refractory rejection: correlation of intragraft cytokine gene expression with pulmonary function and histologic characteristics. Surgery 1995; 118: 385-391.

34. Keenan RJ, Iacono AT, Dauber JH, et al. Treatment of refractory acute allograft rejection with aerosolized cyclosporine in lung transplant recipients. $J$ Thorac Cardiovasc Surg 1997; 113: 335-341 (discussion 340-341).

35. Iacono A, Dauber J, Keenan R, et al. Interleukin 6 and interferon-gamma gene expression in lung transplant recipients with refractory acute cellular rejection: implications for monitoring and inhibition by treatment with aerosolized cyclosporine. Transplantation 1997; 64: 263-269.

36. Iacono AT, Smaldone GC, Keenan RJ, et al. Dose related reversal of acute lung rejection by aerosolized cyclosporine. Am J Respir Crit Care Med 1997; 155: 1690-1698.

37. The Stanford Lung Database Group, the International Lung Transplant Study Group and Novartis Pharmaceuticals. The Novartis Lung Transplant Database White Paper. 1998.

38. Yousem SA, Berry GJ, Cagle PT, et al. Revision of the 1990 working formulation for the classification of pulmonary allograft rejection: lung rejection study group. J Heart Lung Transplant 1996; 15: 1-15.

39. Kaplan EL, Meier P. Nonparametric estimation from incomplete observations. J Am Stat Assoc 1958; 53: 457-481.

40. Cox D. Regression models and life tables. J R Stat Soc 1972; 34: 187-220.

41. Estenne $\mathrm{M}$, Maurer $\mathrm{J}$, Boehler $\mathrm{A}$, et al. Bronchiolitis obliterans syndrome 2001: an update of the diagnostic criteria. J Heart Lung Transplant 2002; 21: 297-310.

42. Moolman JA, Bardin PG, Rossouw DJ, Joubert JR. Cyclosporin as a treatment for interstitial lung disease of unknown aetiology. Thorax 1991; 46: 592-595.

43. Corcoran TE, Dauber JH, Smaldone GC, et al. Relationship between deposited dose and improvement in lung function when aerosol cyclosporine is given as prophylaxis to prevent lung transplant rejection. Am J Respir Crit Care Med 2001; 165: A392.

44. Corcoran TE, Smaldone GC, Dauber JH, et al. Aerosol cyclosporine provides dose dependent improvement in lung function after lung transplantation. J Heart Lung Transplant 2003; 15: Suppl. 1S, S77. 